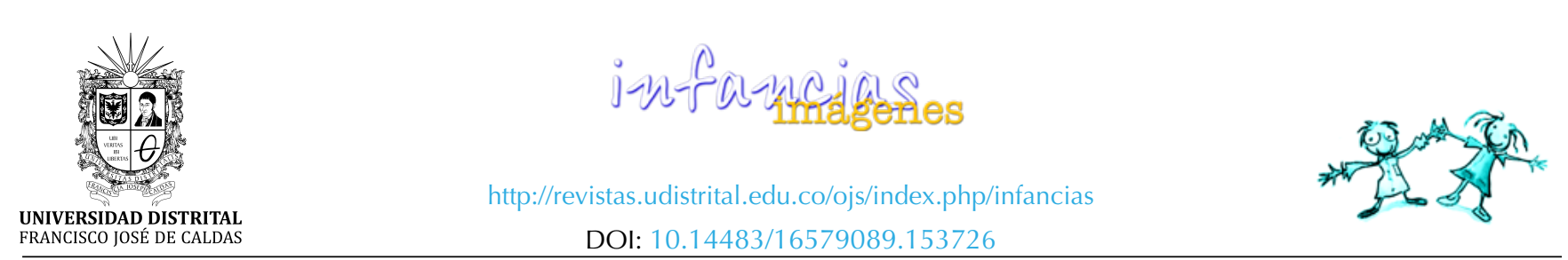

SEPARATA ESPECIAL

\title{
Voces y saberes de niños y niñas frente al conflicto a propósito de la construcción de una cultura de paz*
}

\section{Voices and knowledge of children in the face of the conflict regarding the building of a peace cullture}

\author{
Nicole Andrea Sarmiento Avellaneda ${ }^{1}$
}

\begin{abstract}
Para citar este artículo: Sarmiento, N. A. (2020). Voces y saberes de niños y niñas frente al conflicto a propósito de la construcción de una cultura de paz. Infancias Imágenes, 19(1), 108-120.
\end{abstract}

\section{Resumen}

Esta investigación se gestó desde una metodología cualitativa y tiene como objetivo la comprensión de los saberes de niños y niñas frente al conflicto; dada la importancia que este fenómeno social tiene para la construcción de una cultura de paz. En la investigación se reconoce la trascendencia del papel de los niños y niñas en la transformación de los conflictos, así como del lenguaje, a partir del cual es posible explorar los significados que los niños y niñas han tejido en relación con este fenómeno social. Para el análisis de la información se efectuó un análisis del contenido, en el cual se identificaron categorías como: orígenes del conflicto, posibilidades de transformación y perpetuación de los mismos. La relación entre categorías facilitó la creación de tejidos de significados frente al conflicto, lo que permite repensar iniciativas en relación con la construcción de la tan anhelada cultura de paz.

Palabras clave: infancia, conflicto sociocultural, violencia, cultura de paz.

\begin{abstract}
Albstract
This study, developed from a qualitative methodology, aims to understand the knowledge of children when facing conflict, due to the importance that this social phenomenon has for the construction of a culture of peace. The research recognizes the transcendence of a child's role in the transformation of conflicts, as well as language, from which it is possible to explore the meanings that children have woven? in relation to this social phenomenon. For the information analysis, an examination of the content was carried out, identifying categories such as the origins of the conflict, the possibilities of transformation and perpetuation of the same. The relationship between categories facilitated the creation of different meanings in the face of conflict, which allows us to rethink initiatives in relation to the construction of the long-awaited culture of peace.
\end{abstract}

Keywords: childhood, cultural conflicts, violence, culture of peace.

* Investigación realizada en el marco de la Maestría en Infancia, Universidad Distrital Francisco José de Caldas. Facultad de Ciencias y Educación. Fecha de inicio: mayo de 2018; fecha de finalización: mayo de 2019.

1 Psicóloga de la Konrad Lorenz Fundación Universitaria. Magister en Infancia y cultura de la Universidad Distrital Francisco José de Caldas. nikol.77@hotmail.com. 


\section{Introducción}

Pretender visibilizar las voces y saberes de los niños y niñas en lo concerniente al conflicto (un fenómeno social al cual se le debe prestar absoluta importancia), en tanto las repercusiones que se han vislumbrado en la sociedad por la no posibilidad de transformarlos o asumirlos efectivamente, es sin duda una experiencia creativa que se suma a las múltiples iniciativas gestadas para la construcción de una cultura de paz. Es una expresión de creación, en la cual los niños y niñas dan cuenta del mundo que han tejido en relación con los otros e interpretan sus vidas a partir de la riqueza del lenguaje.

Gracias a estas experiencias creativas en las que los niños y niñas participan como productores y creadores (dando cuenta de sus saberes, es decir, de los significados que han podido hilar frente al conflicto, y que muestra de la evolución del pensamiento y el lenguaje - en tanto que una vez varía el significado de las palabras también lo hará la relación entre pensamiento y palabra一) (Vygotsky, 1987) que se han dado sobre este fenómeno social es posible trazar nuevas reflexiones y prácticas que faciliten los cimientos de una cultura de paz.

De manera que profundizar en los significados que los niños y niñas han tejido en relación con el conflicto permite entrever alternativas de transformación de los mismos y, por ende, posibilita repensar iniciativas para la construcción de una cultura pacífica; la cual está relacionada con la "superación, reducción o evitación de todo tipo de violencias, y con nuestra capacidad y habilidad para transformar los conflictos, para que, en vez de tener una expresión violenta [...] puedan ser oportunidades creativas, de encuentro, comunicación, cambio, adaptación e intercambio" (Fisas, 1998, p. 349).

Entre tanto, pensar el conflicto como una condición para la paz y comprender este fenómeno social desde otras ópticas (en este caso las voces y saberes de niños y niñas que desde la legitimidad de su participación y la riqueza de su imaginación son capaces de crear e innovar realidades que les competen) representa un desafío investigativo que aboca a impulsar nuevos proyectos para la construcción de escenarios pacíficos.
De modo que pensar en una cultura de paz en la cual se reconoce como ineludible el conflicto e imperativa su transformación, en modos constructivos y colectivos, implica una disposición a observar, interpretar, describir y transformar las realidades conflictivas desde nuevas perspectivas. Tales como las que pueden llegar a aportar los niños y niñas, pues como bien refirió Fisas (1998) la transformación aprovecha el conflicto para construir la paz a través de compromisos a largo plazo que deben involucrar a toda una sociedad.

En suma, en este proceso de conocimiento y transformación de los conflictos es indispensable activar rutas desde diversas disciplinas, pero sobre todo desde la creatividad. Siendo mejor desde las voces y saberes de niños y niñas, los cuales pueden develar acciones empáticas, no violentas y novedosas, que favorecen una cultura de paz. Es decir, una cultura de resolución de conflictos permeada no con soluciones de inmediata ejecución ni de eterna aplicación, en tanto las evoluciones y dinámicas de los conflictos, pues:

[...] quienes nos ocupamos en la mediación en los conflictos tenemos que saber que nada es para siempre, [...] el final de un conflicto no impide que se originen otros conflictos. No obstante, no debemos perder la lucidez ni tampoco la esperanza. (Galtung, 2010, p. 20)

\section{Metodología}

Para dar respuesta a la pregunta problema ¿qué características de los saberes de niños y niñas frente al conflicto aportan a la construcción de una cultura de paz?, se hizo una investigación cualitativa. De manera contraria al paradigma cuantitativo (en el que se explican los fenómenos mediante el método deductivo indagando por la justificación de hipótesis a partir de modelos teóricos), busca comprender la realidad social por medio del método inductivo, que parte de lo particular a lo general. En este sentido, la investigación no solo es menos dependiente de conceptos preexistentes que guían el proceso de investigación, sino que se centra en la comprensión de los fenómenos sociales desde 
las experiencias y protagonismo de los actores sociales, de sus producciones discursivas que facilitan el entendimiento e interpretación de las significaciones que se han entretejido sobre el fenómeno estudiado (Izcara, 2014).

Entre tanto, la metodología cualitativa de la presente investigación logró datos descriptivos a partir del lenguaje. Es decir, de las palabras habladas o escritas, así como de la conducta observable; hecho que suscitó en la investigadora una mirada holística de las personas, los contextos o grupos que "no son reducidos a variables, sino considerados como un todo [...] comprendiendo así a las personas dentro del marco de referencia de ellas mismas" (Taylor y Bogdan, 1994, p. 20).

Para el desarrollo de la presente se utilizaron técnicas de investigación de corte cualitativo como la entrevista a profundidad a través de la cual se indagó "minuciosamente la experiencia" de los niños y niñas, mediante los relatos de sus experiencias y con el lenguaje que usa cotidianamente (Robles, 2011).

De igual manera, se contó con la ayuda de grupos focales. Esta herramienta de investigación cualitativa giró en torno al conflicto como temática inicialmente planteada por la moderadora, quien fue la encargada de guiar al grupo en la presentación de preguntas para que emergieran actitudes, sentimientos, experiencias y reacciones de los propios participantes, lo que facilitó la obtención de múltiples puntos de vista y opiniones de quienes integraron el grupo (Escobar y Bonilla, 2017).

Cabe señalar que la investigación se realizó haciendo uso de dos técnicas de investigación. La primera, en tanto que la interpretación de los datos a través de varios ángulos permitió una mayor riqueza en la comprensión del fenómeno de estudio; esto se denomina triangulación de la información e implica el uso de múltiples fuentes para la producción de unos mismos resultados. En el caso de las investigaciones cualitativas, dos técnicas de acopio de material discursivo que logran complementarse de manera efectiva para una debida triangulación son los grupos focales y las entrevistas a profundidad. Técnicas que, como ya se mencionó, fueron utilizadas como parte de la metodología de la investigación (Izcara, 2014).
La muestra de la presente investigación estuvo constituida por niños y niñas de la localidad de San Cristóbal, en Bogotá ${ }^{2}$, con edades entre los 8 a 11 $a_{n}{ }^{3}$. Un tipo de muestra no probabilística que fue utilizada en la investigación correspondió al muestreo por conveniencia, que responde a un tipo de muestreo intencional fundamentado en la selección de participantes más accesibles a la investigadora (Izcara, 2014).

Ahora bien, la estrategia de muestreo más pertinente para el cumplimiento de los objetivos de la investigación (y tomando en cuenta que respondió a un enfoque cualitativo) fue de tipo no probabilístico, en tanto que la finalidad no era la generalización en términos de probabilidad (Hernández et al., 2010).

\section{Resultados}

Una vez efectuadas las entrevistas en profundidad y grupos focales, se transcribió la información, para proteger la identidad de los participantes pero conservando su información en términos de edad y sexo ${ }^{4}$.

Cabe señalar que en las entrevistas en profundidad participaron 30 niños y niñas y en los grupos focales (tres grupos), 19 niños y niñas. En consecuencia, entre ambas herramientas participaron 49 niños y niñas, con edades entre los 8 a 11 años. La muestra final se determinó "por el alcance o superación de un punto de saturación, a partir del cual, incrementos adicionales" en el número de participantes (niños y niñas), no redundaron en nuevos hallazgos o información novedosa (Izcara, 2014, p. 45).

Para el análisis de la información obtenida se hizo una primera lectura de todos los datos, obteniendo así un sentido general de los relatos. El

2 La localidad de San Cristóbal, de donde provenían los participantes, se encuentra ubicada en el sur oriente de la capital colombiana. Limita al norte con la localidad de Santa Fe, al sur con la localidad de Usme, al oriente con los municipios de Choachí y Ubaque y al occidente con las localidades de Rafael Uribe Uribe y Antonio Nariño (Secretaría de Educación, 2017).

3 Los niños y niñas se encontraban vinculados a los programas de la Obra Salesiana del Niño Jesús, organización ubicada en la localidad de San Cristóbal y coordinada por Salesianos de Don Bosco, quienes ofrecen servicios sociales en educación, dirigidos a población infantil, juvenil y adulta en condición de vulnerabilidad.

4 El modo para citar el relato de los participantes fue mediante la regla: sexo ( $\mathrm{M}=$ masculino $/ \mathrm{F}=$ femenino)-número de participante sobre el total de la muestra-edad. Ejemplo: F-05-11; M-07-08. Estas reglas se observarán en el apartado de resultados de la investigación, en la exposición de los relatos de los participantes. 
análisis detallado comenzó con un proceso de codificación (Creswell, 2005), el cual consistió en organizar los datos en categorías. Para ello se efectuó una codificación abierta, de manera que se revisaron todos los segmentos de las entrevistas y grupos focales y se determinaron categorías iniciales de significado con sus respectivas unidades de análisis. Posterior a ello, se hizo una codificación axial que develó la relación entre categorías identificadas a partir de la codificación abierta. Este proceso de codificación se realizó mediante el programa Atlas Ti, información que facilitó la interpretación de los saberes de los niños y niñas, frente al conflicto.

A partir del análisis del contenido, en concreto desde la codificación abierta, se identificaron categorías como: orígenes del conflicto, posibilidades de transformación y perpetuación de los mismos.

Se encuentra que la categoría los orígenes del conflicto está asociada con las emociones y sentimiento desbordados, así como las contradicciones en las relaciones interpersonales (figura 1). Estas asociaciones representan factores que aumentan la probabilidad de aparición u ocurrencia de los conflictos, según los niños y niñas.

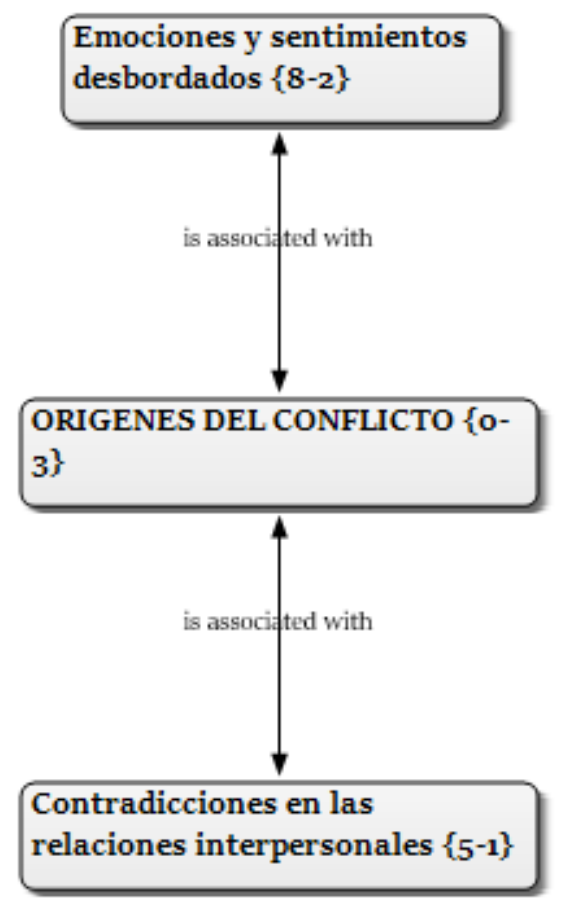

Figura 1. Orígenes del conflicto.

Fuente: elaboración propia de la autora.
En los relatos de los niños y niñas se encuentra información significativa en términos de respuestas emocionales o sentimientos que median las acciones de las partes involucradas en las situaciones de conflicto. Allí los niños y niñas refieren principalmente la emoción de enojo, mediante denominaciones o conceptos como brava, rabia, furia, celos y enojo:

[...] cuando ella se pone brava conmigo ella me hala el pelo. (F-27-11)

[...] a mí me da rabia los cojo y los grito, les pego y les hago de todo. (F-22-10)

[...] nosotras nos puni puni nos ponocamos furiosas le pegamos una patada. (F-07-08)

[...] o sea, se dicen cosas malas, porque es que ellos se enojan. (M-03-08)

[...] la furia lo pone a ser algo agresivo, pega, dice cosas [...] groserías, malas palabras. (M-26-11)

A partir de los relatos de los niños y niñas se logra reconocer la emoción del enojo como un factor que se presenta en las situaciones de conflicto; desde esto se desembocan respuestas violentas que dan cuenta de un repertorio impulsivo mediado por una mente emocional más que una mente racional:

A veces hay algunos adultos que [...] haber los niños a veces no pensamos las cosas antes de hacerlas, hay algunos adultos que no y hay otro que sí y para hablar de rabia hay que pensar [...] los niños o jóvenes peleamos sin pensar. (M-34-09)

Cabe señalar que aunque las emociones son respuestas naturales, que nos llevan a movernos o actuar, de acuerdo con predisposiciones desde lo biológico (sistema límbico) y ambiental (cultural) (Goleman, 1996), son experiencias que podrían estar mediadas por el equilibrio y la interrelación de la mente racional (respuestas reflexivas) y la mente emocional (respuestas impulsivas), para una mayor eficacia en las relaciones inter e intra personales.

Ahora bien, con respecto a la subcategoría contradicciones en las relaciones interpersonales, se identifican dos elementos particulares relacionados con los orígenes del conflicto.

El primer elemento refiere a la naturalidad del conflicto a partir de la condición de la humanidad, 
que marcada por diferencias e incompatibilidades está en constante predisposición de verse involucrada en situaciones conflictivas. Como bien refiere uno de los participantes:

Los conflictos existen porque es que nadie es perfecto y la verdad digamos digamos yo tampoco soy perfecto, pues algunos nacen más bravos, algunos son más buenos y así, no todos somos iguales y algunos tienen un carácter bravo, duro. (M-45-11)

El segundo elemento entrevé que un conflicto se cimienta en las relaciones interpersonales, en tanto que es a partir de estas interacciones sociales que se presentan los desacuerdos, incompatibilidades o diferencias que pueden desencadenar la situación conflictiva:

Mmm cuando las personas se pelean o algo así parecido [...] o sea, cuando no les parece algo a él o una persona que pues no tienen las mismas opiniones debido a que da cuenta de los "átomos" del mismo, en términos de disputa (cuando se persigue un mismo fin que escasea) y dilema (cuando se persiguen dos fines incompatibles entre sí). Cualquiera de estos elementos atómicos puede originar el conflicto, el cual tiene la posibilidad de ser abordado mediante estrategias de transformación (Galtung, 2008).

Entre tanto, para los niños y niñas los conflictos pueden darse en cualquier escenario de la vida; debido a que en todos los contextos donde se desenvuelve la humanidad hay una mediación social o de relaciones interpersonales, marcadas por contradicciones, diferencias o incompatibilidades que hacen más susceptible la aparición de una situación conflictiva.

Por su parte, la categoría transformación del conflicto se encuentra asociada con los agentes mediadores en el conflicto, el perdón como punto de encuentro, la mente reflexiva que toma conciencia y el consenso fruto del diálogo (figura 2). Estas categorías facilitan, desde los significados que han construido los niños y niñas, la comprensión de estrategias de transformación efectiva de los conflictos. Es decir, alternativas no violentas, empáticas y creativas que se logran ajustar a las condiciones de to fundamental en la comprensión del conflicto,

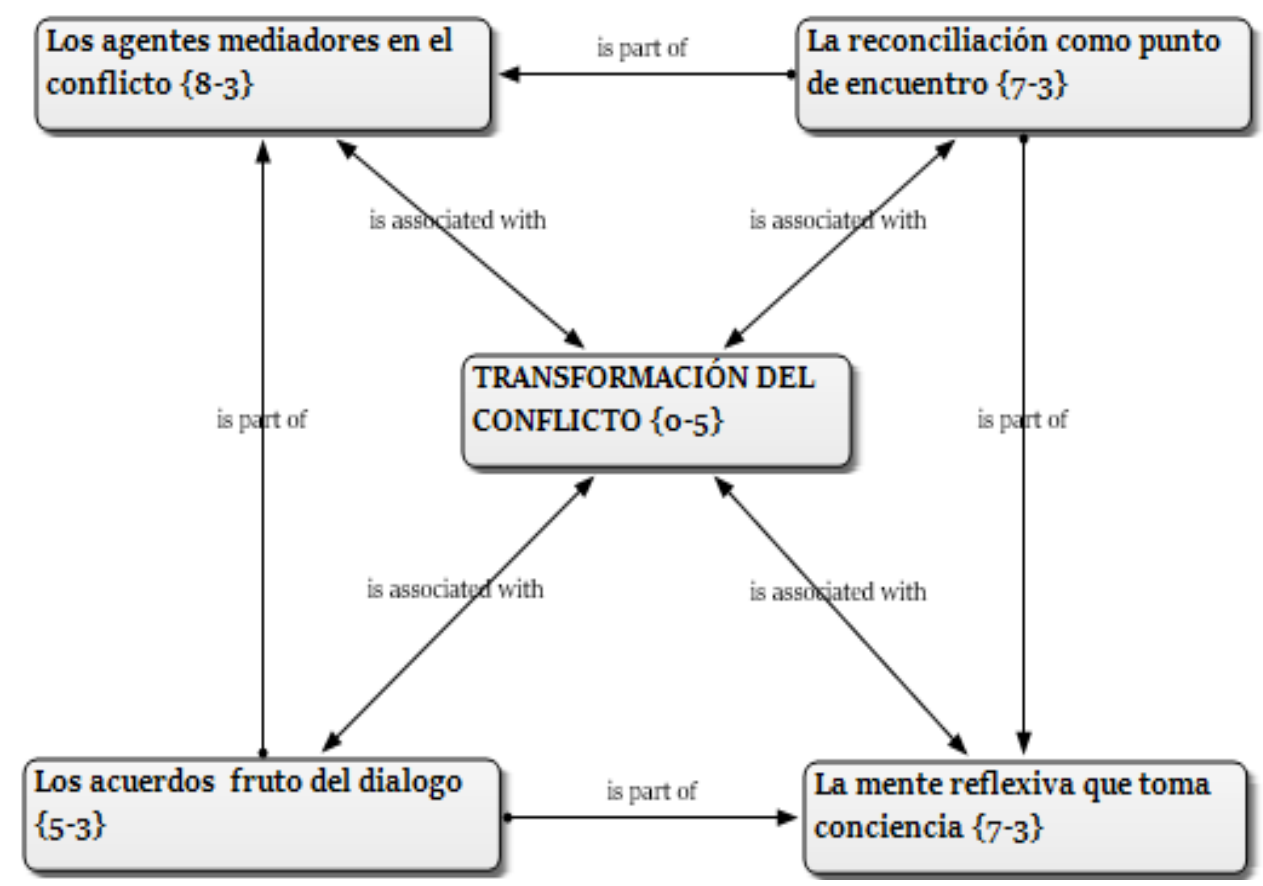

Figura 2. Posibilidades de transformación del conflicto.

Fuente: elaboración propia de la autora. 
los conflictos (como sus orígenes o características), transformándolos y, de esta manera, posibilitando la construcción de una cultura de paz.

La subcategoría los agentes mediadores en el conflicto, gestada a partir de los relatos de los niños y niñas, logra exponer la función de los mediadores que logran a partir del poder de la palabra, dar orientaciones a quienes se encuentran en la situación conflictiva; facilitando así la transformación efectiva de la misma y la disminución del daño no solo para las partes directamente involucradas, sino para aquellos que de manera indirecta se pueden encontrar inmersos en dichas realidades. Al respecto, uno de los participantes que manifiesta durante la entrevista en profundidad una situación de conflicto dentro de su contexto familiar, en este caso entre sus padres, muestra la importancia de estos mediadores en relación con la transformación de los conflictos:

[...] que no peleen más, que yo estoy sufriendo [...] que vayan a un psicólogo, que piensen en sus hijos que sus hijos están sufriendo, que vayan a hablar con una persona que sí les ayude. (F-12-09)

Se evidencia que la puesta en escena de los actos de mediación del conflicto solo puede llevarse a cabo mediante el acto de la palabra. Es decir, según los relatos de los niños y niñas, es necesario que quien esté involucrado en el conflicto se movilice en búsqueda de la tercera parte (en este caso el mediador), relatándole (poder de la palabra) la situación conflictiva, para que de esta manera se puedan tejer estrategias de afrontamiento:

Que vayan a hablar con una persona que sí les ayude. (F-12-09)

Respecto a la subcategoría la reconciliación como punto de encuentro, esta es sin duda para los niños y niñas un mecanismo de transformación del conflicto, en tanto que a partir del poder de las palabras perdón, disculpa y reconciliación se logra un nuevo comienzo con el otro. Es decir, una transformación en la relación interpersonal, que a pesar de la situación conflictiva es capaz de tejer nuevos caminos de paz. Bien refiere una de las participantes:
Perdonarlo es como dejar lo que pasó antes y comenzar digamos un nuevo compañerismo, una nueva amistad. (F-24-11)

En consecuencia, se habla del dominio de la palabra en los caminos de transformación de los conflictos. Debido a que los niños y niñas aseguran que, tras la emisión de actos que denominan conflictivos, la expresión reconciliación, con sus diversas conjugaciones, ejerce un poder de transformación en la situación conflictiva:

Pues es que digamos uno le pega a otra persona y tiene que decirle me perdonas por favor, o sea tiene, que decirle perdón, eh o sea, que no le vuelva a pegar. (M-16-09)

Cabe señalar que para los niños y niñas es tan significativo el poder de la palabra reconciliación (en sus diversas conjugaciones) en los procesos de transformación de un conflicto, que aseguran que tras la emisión de estos actos de habla la situación de conflicto no solo debe resolverse sino además prevenirse. Incluso, algunos niños hacen uso de expresiones poéticas frente a la reconciliación como un ejercicio que denominan se debe gestar desde "el corazón" para de esta manera garantizar una no repetición del daño:

O sea, es como si alguien le pegó, pero, o sea, es perdonar pero de corazón, porque si él lo vuelve a hacer, o sea, ya no sería un perdón, perdón de corazón de que uno no vuelva a hacer eso. (F-02-08)

En cuanto a la subcategoría la mente reflexiva que toma conciencia se encuentra a partir de los relatos de los niños y niñas, la trascendencia frente a la emisión de acciones bajo una mente reflexiva para la transformación de la situación conflictiva. En tanto que a partir de esta "reflexión o acto de pensar" (como lo denominan los participantes) se facilita la emisión de respuestas menos impulsivas y por ende nocivas en términos de consecuencias a corto y largo plazo:

No, pues solo que hay que reflexionar sobre las cosas, no solo lo que se me viene directo a la cabeza hacer, sino pensar en lo que voy a hacer realmente. (F-28-11) 
Ahora bien, la subcategoría los acuerdos fruto del diálogo que emerge de los relatos de los niños y niñas devela que los compromisos que asumen las partes del conflicto a partir de consensos que se toman de manera conjunta en escenarios discursivos o de diálogo mediados por el poder de la palabra son sin duda facilitadores para la transformación del conflicto. Además, reconocen que en estos acuerdos pueden incluirse no solo a las personas directamente involucradas o afectadas, sino también aquellas que pueden tener de manera indirecta parte en la situación conflictiva y, por ende, deben también ser tenidas en cuenta:

Pues yo haría que se hiciera como una fundación a los niños que se portaran mal y hacerlos como un compromiso y citar a los papás que también hagan un compromiso con ellos, de pronto ellos también pueden arreglar a los niños, o sea, que no los deseduquen más, porque algunos niños son y las mamás no los educan bien entonces podemos que pueden que mejorar eso. (M-18-10)

También, los niños y niñas aseguran que el acuerdo mediado por el acto del habla debe estar supeditado al acto de escucha. De ahí que las voces de todas las partes del conflicto sean tenidas en cuenta. La posibilidad de escuchar y hablar con el otro es sin duda para los niños y niñas un factor relevante; tanto así que en sus relatos se evidencia de manera reiterativa el uso de estos conceptos que en últimas develan la riqueza del lenguaje en la transformación de conflictos a propósito de una cultura de paz:

Buscar el conflicto [...] Escuchar, digamos si están peleando dos primos, escuchar qué fue lo que pasó, qué es lo que tiene que decir él y qué es lo que tiene que decir el otro, para así encontrar la solución. (M-31-11)

Por otro lado, se encuentra la categoría perpetuación del conflicto, la cual se encuentra asociada con la violencia directa como mecanismo de daño físico y psicológico, mecanismos fallidos de castigo y las voces de los niños y niñas que no se escuchan (figura 3). Estas subcategorías develan mecanismos a partir de los cuales subsisten los conflictos, mediante prácticas nocivas que responden a una cultura de violencia.

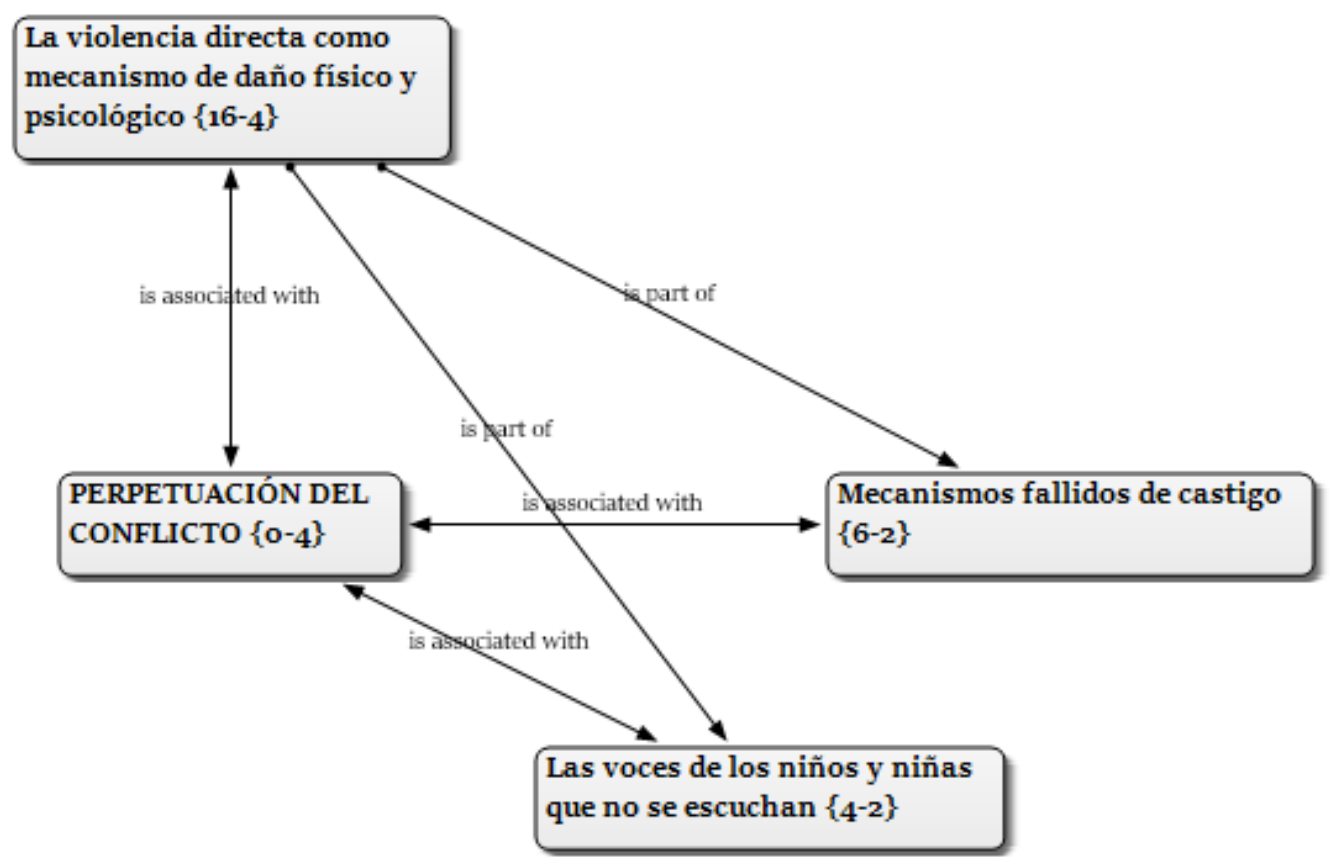

Figura 3. Posibilidades de perpetuación del conflicto.

Fuente: elaboración propia de la autora. 
La subcategoría la violencia directa como mecanismo de daño físico y psicológico devela que los niños y niñas han otorgado al concepto de conflicto un significado desde los sucesos violentos (utilizando conceptos como pegar o pelear), de ahí que comprendan el conflicto, en la mayoría de los casos, como un sinónimo de la violencia.

Respecto a la subcategoría mecanismos fallidos de castigo se identifican acciones por parte de los adultos que se presentan aparentemente bajo la intención de castigo (desde el condicionamiento operante $\mathrm{e}^{5}$ es visto como una consecuencia que busca extinguir o eliminar una conducta) hacia las conductas violentas de los niños y niñas; pero con la clara revelación de ser intentos fallidos, en tanto que las conductas que aparentemente están castigando siguen mantenidas en el tiempo.

Cabe señalar que las acciones de los adultos (en el contexto escolar), mayoritariamente referidas por los niños y niñas, corresponden a anotaciones en el observador (este concepto se presentó durante 26 veces en los relatos de los niños y niñas): sanciones o expulsiones. No obstante, los niños y niñas aseguran que en la mayoría de los casos estas conductas, que como ya se refirió responden aparentemente a estrategias de castigo, no garantizan la extinción de los conflictos permeados por repertorios violentos (física o psicológica). Al respecto, uno de los participantes de las entrevistas en profundidad, ante la pregunta "y en el colegio, ¿cómo resuelven los problemas?", refiere:

Le escriben en el observador, lo tienen que escribir y si lo citan y después si dice que no, no quiero a esa niña lo expulsan [...] no vuelve más. (M-04-08)

Adicionalmente, ante la contra pregunta: "¿tú crees que eso ayuda a solucionar los problemas?", asegura: No porque se están peleando.

De manera que acciones de aparente castigo, por parte de los adultos dentro del contexto escolar, no son interpretadas por los niños y niñas como estrategias que garanticen la transformación efectiva de los conflictos (los cuales responden a actos violentos entre pares dentro del contexto escolar),

5 Modelo teórico propuesto por Skinner (1938), citado en Ardila (2001). sino que por el contrario a la perpetuación de los mismos:

Sí, en el salón hay un compañero, emm ¿cómo es que se llama?, bueno no me acuerdo el nombre, pero un día él le dijo a una compañera que era una puta, que porque se la gozaba con todos que nada le importara si la vieran, entonces pues ella se sintió muy mal y pues decidió decirle a los profesores, y pues los profesores hicieron algo, pero el niño la seguía tratando mal y ya después no fue con ella sino fue con otra compañera y así así hasta con todos los del salón. (F-24-11)

En cuanto a la subcategoría las voces de los niños (as) que no se escuchan se devela cómo el acto del habla de los niños y niñas es supeditado al de los adultos, quienes en las situaciones de conflicto soslayan la posibilidad de participación de los niños y niñas ante los asuntos o realidades que les competen.

De ahí que los niños y niñas aseguren que no logran exponer su palabra, en tanto que los adultos no asumen el papel de receptores (por medio de la escucha). Lo que quebranta los canales de comunicación entre infancias y adultos, así como la posibilidad de garantizarles a los niños y niñas su interés superior y ejercicio de participación ${ }^{6}$ :

Nos deberían escuchar porque somos parte del problema; aunque digan que no es nuestro problema, también es nuestro problema. (F-35-11)

Nos deberían escuchar porque podemos a veces tener la razón. (M-36-09)

Para los niños y niñas la posibilidad de transformación de un conflicto es más que una utopía; es una realidad siempre latente que puede perder fuerza en la medida en que (gracias al adultocentrismo) los adultos ignoran ideas creativas gestadas de los saberes de niños y niñas, quienes con intención de pronunciarse por medio de la palabra, pueden contribuir en la construcción de escenarios de transformación de las situaciones conflictivas por medio de la empatía, la no violencia y la creatividad.

6 Ley 1089 de 2006. Por la cual se expide el código de la infancia y la adolescencia, y Convención sobre los Derechos del niño. 
Por otra parte, se identificaron mediante la codificación axial diversas relaciones entre categorías como los agentes mediadores en el conflicto, junto con la reconciliación como punto de encuentro y los acuerdos fruto del diálogo.

Se encuentra que, para los niños y niñas, es posible la transformación de los conflictos a partir de la relación de los procesos de mediación y la reconciliación que se puede cimentar desde una situación conflictiva. Es decir, cuando un tercero (mediador) a partir del poder de la palabra anima a las partes del conflicto a reconciliarse a través del acto del habla, la probabilidad de lograr una transformación no violenta del conflicto es mayor.

Frente a la relación de los procesos de mediación y los acuerdos se encuentra que, para los niños y niñas, es posible el establecimiento de iniciativas de transformación de los conflictos cuando un tercero (mediador) al practicar el poder de la palabra, incita a las partes del conflicto a establecer acuerdos, compromisos o consensos que les represente de algún modo u otro un beneficio.

Por otro lado, se encuentra la posibilidad de construir una cultura de paz mediante una transformación efectiva del conflicto, a partir de la relación entre las categorías: mente reflexiva que toma conciencia, con la reconciliación como punto de encuentro y los acuerdos fruto del diálogo.

Respecto a la relación entre la mente reflexiva y la reconciliación se encuentra que es más probable la emisión de actos de reconciliación cuando las partes evalúan la situación conflictiva, desde la mente reflexiva (armonía entre lo emocional y racional) más que desde un repertorio impulsivo (solo mente emocional). De manera que, a mayor acción de reflexión, mayor acción de reconciliación.

En cuanto a la relación entre la mente reflexiva y los acuerdos se identifica que al asumir una postura que equilibre la mente emocional y racional (dejando de lado respuestas impulsivas que dan cuenta de una mente más emocional —actuar sin pensar, como aseguran los niños y niñas-) es más probable la identificación de alternativas que provocan mayores beneficios y menores daños en las partes involucradas en el conflicto. Esto lograría una transformación y, por ende, una respuesta a la construcción de una cultura de paz.
Por otra parte, se identifica la relación entre las categorías violencia directa, como mecanismo de daño físico y psicológico, con las emociones y sentimientos desbordados, los mecanismos fallidos de castigo y las voces de los niños y niñas que no se escuchan. Esta correspondencia, contraria a las relaciones mencionadas antes, entrevé la posibilidad de no lograr una transformación efectiva de los conflictos y así construir una cultura de violencia nociva para la humanidad.

Con respecto a la relación entre violencia directa y las emociones se encuentra que las personas bajo la mente emocional (actuar sin pensar) activan respuestas impulsivas que hacen más probable la ocurrencia de eventos adversos. De ahí que, en la medida en que se logre una mejor regulación de las emociones existe una mayor probabilidad de encontrar respuestas violentas.

En cuanto a la relación entre violencia directa y mecanismos fallidos de castigo se ve que la imposibilidad de repensar y ejecutar consecuencias acordes a los repertorios conductuales y realidades de las personas que se encuentran involucradas en una situación conflictiva (establecida como actos agresivos según los relatos de los niños y niñas), facilita el mantenimiento de conductas disfuncionales $y$, por ende, el establecimiento de prácticas culturales violentas que terminan orientando los lenguajes y saberes de aquellos que se encuentren inmersos en estos contextos.

Finalmente, la relación entre violencia directa y las voces de los niños y niñas que no se escuchan expone cómo a partir de acciones adultocentricas, que entorpecen los actos de habla de los niños y niñas, se mantienen acciones violentas que imposibilitan la transformación efectiva de los conflictos. Es decir, en la medida en que se oculten las voces (permeadas por iniciativas creativas, empáticas y no violentas) de los niños y niñas, la posibilidad de sostenibilidad de un conflicto y de una construcción de cultura violenta es mayor.

\section{Conclusiones}

Desde los relatos de 49 niños y niñas fue posible movernos en la palabra a partir de hechos creativos que visibilizaron tejidos de significados que han 
construido en relación con el conflicto. Se identificaron así experiencias, conocimientos y acciones frente a este fenómeno social que facilitan y dificultan la construcción de una cultura de paz.

Gracias a la producción de conocimiento de los niños y niñas, protagonistas de estas creaciones, es posible una vez más reconocer la riqueza del lenguaje $^{7}$ en la comprensión y transformación de asuntos que nos interpelan. Tal es el caso del conflicto, que a partir del poder de la palabra es susceptible de transformación constante; pues como bien refieren los niños y niñas, a través del lenguaje, del acto del habla, se construyen procesos de mediación, reconciliación y acuerdos que responden a acciones no violentas, empáticas y creativas.

Mediante los relatos de los niños y niñas fue posible comprender que el conflicto como fenómeno social tiene sus orígenes en experiencias humanas como las emociones, sentimientos y las contradicciones en las relaciones interpersonales. De ahí que el conflicto en sí mismo represente una realidad natural y propia de la condición humana, tal como lo asegura Tonucci (2008); uno de los elementos más ricos que tenemos nosotros los seres humanos $y$, por ende, un tesoro que en la medida en que sepamos encontrarlo y utilizarlo, generará grandes beneficios, como la cimentación de una cultura de paz.

Por consiguiente, si el conflicto tiene sus orígenes en emociones y sentimientos, como el enojo o los celos, así como en las contradicciones dadas en la interacción con el otro, es necesario que como sociedad nos eduquemos en el afrontamiento efectivo de las emociones y de las contradicciones que se pueden entramar durante toda la historia de aprendizaje de cada individuo.

De ahí que la construcción de una cultura de paz desde experiencias educativas, como las cátedras de paz $^{8}$, cimente con mayor ímpetu una cultura de resolución de conflictos a partir del entrenamiento de habilidades como la regulación emocional, que ayuda a reconocer con mayor claridad las emociones y asumirlas sin juicios, así como la eficacia interpersonal que implica una conducta socialmente

7 Lenguaje y narrativas infantiles, énfasis en el que se inscribió la presente investigación

8 Decreto 1038 de 2015 y Ley 1732 de 2014. Según los cuales es importante abordar el componente de resolución pacífica de conflictos. habilidosa para expresar creencias, necesidades, establecer límites y negociar transformaciones a los problemas, sin hacer daño a otros ni a sí mismos (Linehan, 2015).

Por otro lado, gracias a la producción de conocimiento por parte de los niños y niñas participantes de esta investigación, se encuentran otras posibilidades de transformación de los conflictos, como los agentes mediadores (una tercera persona en el conflicto que facilite a partir de la riqueza del lenguaje). Es decir, del acto del habla, la reconciliación entre las partes del conflicto y los acuerdos entre estas.

De modo que es necesario profundizar en este campo de la mediación en diversos escenarios de la sociedad, pues aunque se reconocen figuras mediadoras como: comisarios de familia (para los conflictos intrafamiliares, mediados por violencia intrafamiliar $)^{9}$, comités de convivencia laboral ${ }^{10}$ (para los conflicto laborales mediados por actos de acoso laboral), programa Hermes ${ }^{11}$ y comités escolares de convivencia ${ }^{12}$ (para los conflictos mediados por violencia escolar), es fundamental ahondar en el conocimiento referente a la formación de estos agentes y el impacto de los procesos de mediación en términos de prevención de prácticas violentas y transformación efectiva de conflictos que aporten a la construcción de una cultura de paz.

Vale la pena señalar que, para los niños y niñas, los mediadores (a través del acto del habla) posibilitan la transformación efectiva de los conflictos, en tanto que permiten a las partes del conflicto entrar en dinámicas de reconciliación y acuerdos. No obstante, es importante preguntarnos desde el campo de la investigación si los agentes mediadores de los conflictos, en los diferentes escenarios como familia, trabajo y colegio, realmente facilitan a partir del poder de la palabra estas experiencias

9 Ley 575 de 2000, por medio de la cual se reforma parcialmente la Ley 294 de 1996.

10 Resolución 652 de 2012.

11 Propuesta pedagógica del Centro de Arbitraje y Conciliación de la Cámara de Comercio de Bogotá, gestada desde el 2001; con el objetivo de construir una cultura sin violencia y el reconocimiento de nuevas formas de manejo del conflicto en los colegios, mediante la participación de diversas figuras. En esta se presta mayor atención a los estudiantes, quienes están llamados a liderar (a partir de programas de formación) los procesos de resolución de conflictos de manera pacífica.

12 Ley 1620 de 2013. 
asociadas a los acuerdos y reconciliación entre las partes, previniendo así escenarios que respondan a una cultura de violencia.

Al hablar de reconciliación, los niños y niñas reconocen esta acción como una garantía de no repetición del daño y de transformación de las relaciones interpersonales, que develan una oportunidad de mejora para las partes involucradas en el conflicto. De manera que el significado que han construido los niños y niñas frente a la reconciliación, gestada a partir del poder de la palabra como posibilidad de transformación de los conflictos, entrevé una estrategia efectiva para la evolución de las relaciones sociales y del progreso de la humanidad.

Frente a los acuerdos entre las partes del conflicto, establecidos a través de los agentes mediadores, se encuentra que los niños y niñas aseguran que los acuerdos determinados a partir del acto del habla deben estar supeditados al acto de escucha. De ahí que las voces de los implicados en el conflicto sean tenidas en cuenta, logrando la inclusión de todas

118 las partes del conflicto en la gestación de un nuevo proyecto en el cual todos se reconozcan. Estos proyectos novedosos deben estar mediados por acciones empáticas, no violentas y creativas, que al responder a una cultura de resolución de conflictos facilitan el cimiento y perpetuación de una cultura de paz (Galtung, 2010).

Para los niños y niñas la reconciliación y los acuerdos, además de ser parte de los procesos de mediación, están relacionados con la mente reflexiva; otro factor trascendental para la transformación de conflictos, en tanto que a partir de esta reflexión $o$ acto de pensar (como lo denominan los participantes) se facilita la emisión de respuestas (ante el conflicto) menos impulsivas y perjudiciales para el individuo y la sociedad. De modo que tanto la reconciliación como el establecimiento de acuerdos representan repertorios conductuales funcionales para la transformación del conflicto que, al ser mediados por la mente reflexiva, se aíslan de comportamientos agresivos que pueden desembocar una cultura de violencia.

Sin embargo, a raíz de estas nociones de los niños y niñas en relación con la mente reflexiva como factor preponderante para la emisión de actos de reconciliación y de acuerdos (que se suscitan y mantienen gracias al poder lenguaje), para la transformación no violenta, empática y creativa de los conflictos surge una vez más la posibilidad de cuestionarnos si actualmente nos estamos formando de manera constante e ineludible en el campo de la inteligencia emocional, donde se logra un equilibrio y armonía entre la mente emocional con la mente racional, para la emisión de comportamientos más pacíficos ante situaciones de conflicto (Goleman, 1996).

Por otro lado, a partir de la creación y producción de los relatos de los niños y niñas se encontraron mecanismos de perpetuación del conflicto que han sido asociados a la violencia directa; a partir de una situación conflictiva las personas suelen emitir repertorios conductuales violentos en términos físicos y psicológicos. Esta violencia que fue relatada principalmente en los escenarios familiar y escolar se refiere a la imposibilidad de transformar efectivamente los conflictos (Fisas, 1998) y, así, perpetuarlos en tiempo y lugar. Según los niños y niñas, estos actos violentos que forman parte de un afrontamiento inadecuado de las emociones y sentimientos, de mecanismos fallidos de castigo y de la imposibilidad para escuchar las voces de los niños y niñas, son sin lugar a duda posibilidades de permanencia de los conflictos que, al no llegar a ser transformados, forjan prácticas de violencia.

De acuerdo con los relatos de los niños y niñas, los mecanismos fallidos de castigo perpetúan los conflictos, en tanto que son acciones que en su mayoría emiten los adultos tras situaciones de conflicto, con la intención de castigar las conductas violentas de los niños (desde el condicionamiento operante, el castigo es visto como una consecuencia que busca extinguir o eliminar una conducta ${ }^{13}$ ). Sin embargo, logran un efecto contrario al deseado, debido a que consiguen que los conflictos se mantengan junto con los comportamientos violentos que los acompañan, formando parte de los repertorios conductuales de las personas y, por esta razón, construyendo prácticas culturales violentas.

Lo anterior abre caminos a futuras investigaciones que logren dar cuenta de las consecuencias que reciben las personas vinculadas a una situación de

13 Modelo teórico propuesto por Skinner (1938), citado en Ardila (2001). 
conflicto, relacionada con actos violentos, identificando si estos efectos son acordes a su realidad y, por ende, funcionan como castigos (desde lo planteado por el condicionamiento operante ${ }^{14}$ que facilitan la disminución o extinción permanente de repertorios conductuales que responden a una cultura de violencia; o si por el contrario se establecen mecanismos de corrección regulados que se aíslan de las heterogeneidades de cada individuo $y$, por consiguiente, la posibilidad de forjar prácticas realistas, creativas, empáticas y no violentas.

Adicionalmente, se identifica desde los relatos que otro mecanismo que perpetua los conflictos son las voces de los niños y niñas que no se escuchan. Esto devela cómo el acto del habla de los niños y niñas es supeditado al acto de los adultos, quienes en las situaciones de conflicto eluden la posibilidad de participación de los niños y niñas ante los asuntos que les competen. Esta realidad centrada en el adultocentrismo imposibilita la puesta en escena de estrategias no violentas y creativas para el afrontamiento de los conflictos, desde las voces de los niños y niñas, quienes, mediante la riqueza del lenguaje (es decir, el poder de su palabra, su ejercicio de participación y su producción de conocimiento), son sujetos activos en su propia cultura capaces de la transformación de las realidades que les interpelan.

En consecuencia, invisibilizar las voces y saberes de los niños y niñas como productores ricos en relatos y conocimientos frente a un fenómeno social como el conflicto es, sin duda, un mecanismo de ceguera cultural que nos impide identificar y repensar de manera constante iniciativas para la transformación no violenta y creativa de los conflictos. La posibilidad de continuar perpetuando una cultura de violencia es lo que nos distancia de la tan esperada cultura de paz.

De modo que, si tuviéramos en cuenta los saberes de los niños y niñas frente al conflicto expuestos mediante el poder del lenguaje, podríamos encontrarnos con otras significaciones que nos aproximan a la identificación de nuevos mundos y nuevas preguntas que se ajustan a las transiciones y complejidades de este fenómeno social; a nuevas

14 Ibid. transformaciones y no soluciones definitivas. Pues, como asegura Galtung (2010), con los conflictos no podemos perder la lucidez, pero mucho menos la esperanza: "quienes nos ocupamos en la mediación en los conflictos tenemos que saber que nada es para siempre, [...] el final de un conflicto no impide que se originen otros conflictos" (p. 20).

En suma, repensarnos en las realidades de los conflictos desde la producción del conocimiento de los niños y niñas y desde la riqueza de su lenguaje nos posibilita construir nuevos escenarios de una cultura de paz, a entender que el conflicto es una realidad humana, con posibilidades de transformación, pero también de perpetuación. De manera que, si sabemos comprender estos tejidos de significados, encontraremos en el conflicto una riqueza para la humanidad. Como bien lo refiere una de las participantes:

[...] el conflicto en sí es como una experiencia [...] porque hay un dicho: lo que no mata lo hace más fuerte; y pues a mí me hizo mucho más fuerte. (F-24-11)

\section{Referencias}

Ardila, R. (2001). Psicología del aprendizaje. Siglo Veintiuno.

Creswell, J. (2005). Educational research: Planning, conducting and evaluating quantitative and qualitative research. Pearson Education.

Escobar, J. y Bonilla F. (2017) Grupos focales: una guía conceptual y metodológica. Cuadernos hispanoamericanos de Psicología. Universidad del Bosque. https://palenque-de-egoya.webnode.es/_files/200000286-47b1249946/Grupo\%20focal.pdf

Fisas, V. (1998). Cultura de paz y gestión de conflictos. Icaria.

Galtung, J. (2008). Handbook of conflict analysis and resolution. Routledge.

Galtung, J. (2010). Investigación para la paz y conflictos: presente y futuro. Ponencia y síntesis del diálogo, por la organización del SIP.

Goleman, D. (1996). Inteligencia emocional. Kairos.

Hernández, R., Fernández., C. y Baptista, M. (2010). Metodología de la Investigación ( $5^{a}$ edición). McGraw-Hill. 
Izcara, S. (2014). Manual de investigación cualitativa. Fontamara.

Linehan, M. (2015). DBT-Skills Training Manual. The Guilford Press.

Robles, B. (2011). La entrevista en profundidad: una técnica útil dentro del campo antropofísico . Cuicuilco, 18(52), 39-49.

Secretaría de Educación (2017). San Cristóbal Localidad 4: caracterización sector educativo año 2017. https:// www.educacionbogota.edu.co/portal_institucional/
sites/default/files/inline-files/4-Perfil_caracterizacion_localidad_San_Cristobal_2017.pdf

Taylor, S. y Bogdan, R. (1994) Introducción a los métodos cualitativos de investigación. Paidós.

Tonucci, F. (2008). Evaluación y nuevas perspectivas del proyecto "La Ciudad de los Niños". En, V Encuentro La Ciudad de los Niños. La infancia y la ciudad: una relación difícil (p. 113). http://www.de0a18.net/pdf/ doc_participacio_v_encuentro.pdf

Vygotsky, L. (1987). Pensamiento y lenguaje. La Pléyade. 